\title{
Combinatorial approaches with selected phytochemicals to increase antibiotic efficacy against Staphylococcus aureus biofilms
}

\author{
Ana Cristina Abreu ${ }^{\mathrm{a}}$, Maria José Saavedrab ${ }^{\mathrm{b}}$, Lúcia C. Simões ${ }^{\mathrm{a}, \mathrm{c}}$ and Manuel Simões ${ }^{\mathrm{a}}$ (D) \\ aLEPABE, Department of Chemical Engineering, Faculty of Engineering, University of Porto, Porto, Portugal; ${ }^{b} C E C A V$, Veterinary and Animal \\ Science Research Center, Quality and Food Safety of Animal Products Group, University of Trás-os-Montes and Alto Douro, Vila Real, Portugal; \\ 'CEB - Centre of Biological Engineering, University of Minho, Braga, Portugal
}

\begin{abstract}
Combinations of selected phytochemicals (reserpine, pyrrolidine, quinine, morin and quercetin) with antibiotics (ciprofloxacin, tetracycline and erythromycin) were tested on the prevention and control of Staphylococcus aureus biofilms. The phytochemicals were also studied for their ability to avoid antibiotic adaptation and to inhibit antibiotic efflux pumps. Morin, pyrrolidine and quercetin at subinhibitory concentrations had significant effects in biofilm prevention and/or control when applied alone and combined with antibiotics. Synergism between antibiotics and phytochemicals was found especially against biofilms of NorA overexpressing strain S. aureus SA1199B. This strain when growing with subinhibitory concentrations of ciprofloxacin developed increased tolerance to this antibiotic. However, this was successfully reversed by quinine and morin. In addition, reserpine and quercetin showed significant efflux pump inhibition. The overall results demonstrate the role of phytochemicals in co-therapies to promote more efficient treatments and decrease antimicrobial resistance to antibiotics, with substantial effects against $S$. aureus in both planktonic and biofilm states.
\end{abstract}

ARTICLE HISTORY

Received 10 May 2016

Accepted 31 August 2016

\section{KEYWORDS}

Antibiotic adaptation; antibiotic resistance; biofilms; efflux pump; phytochemicals; Staphylococcus aureus

\section{Introduction}

The widespread use of antibiotic-resistance elements among bacterial pathogens has made the treatment of some infections a serious concern. Indeed, many diseases that were once easily treatable have become deadly again (Brown \& Wright 2016). It is clear from the past two decades of efforts that developing new, highly effective, safe and broad spectrum antibiotics has been an impossible task (IDSA 2011). New strategies are emerging to control microbial growth, including the use of combinations of therapeutic agents. The use of molecules antagonizing bacterial resistance mechanisms is a promising way to ensure the efficacy of antibiotics. Augmentin (amoxicillin-clavulanic acid), Timentin ${ }^{\circledR}$ (ticarcillin-clavulanic acid), Unasyn ${ }^{\oplus}$ (ampicillin-sulbactam) and Tazocin ${ }^{\oplus}$ (piperacillin-tazobactam) are successful examples of combinatorial therapies effective against multidrug resistant strains (Abreu et al. 2013; Lewis 2013). More recently, combined treatments between antibiotics and plant secondary metabolites showed promising results and represent an increasingly active research topic (Abreu et al. 2012, 2014, 2015). Plant-based systems continue to play an essential role in healthcare, and their ethnopharmacological use has been extensively documented (Cragg \& Newman 2013). Numerous reports can be found on non-antimicrobial plant secondary metabolites that act as adjuvants in therapy, especially due to the inhibition of microbial resistance mechanisms, but also due to an overall improved solubility and stability of the active compounds (Gibbons et al. 2003; Mullin et al. 2004; Oluwatuyi et al. 2004; Abreu et al. 2012). In previous studies, three alkaloids - reserpine, pyrrolidine and quinine - and two flavonoids - morin and quercetin - at sub-inhibitory concentrations have shown to potentiate ciprofloxacin, tetracycline and erythromycin against diverse antibiotic resistant strains of $S$. aureus in the planktonic state, including methicillin-resistant S. aureus (MRSA), presenting acceptable cytotoxicity (Abreu et al. 2014, 2015). Reserpine has been receiving much attention as an efflux pump inhibitor (EPI), despite some toxicity issues (Schmitz et al. 1998; Markham et al. 1999; Gibbons \& Udo 2000). However, to the authors' knowledge, its effect was never tested against biofilms. Indeed, antimicrobial resistance is increased when microorganisms form biofilms (Olson et al. 2002; Burmolle 
et al. 2006; Verstraeten et al. 2008). It is estimated that $>80 \%$ of bacterial infections in humans involve the formation of biofilms (Brooun et al. 2000; Simoes et al. 2008; Busetti et al. 2010). Moreover, antimicrobial studies using planktonic cells despite having provided extensive information describing the mechanisms inhibiting bacterial growth may not be enough to predict therapeutic success (Pratt \& Kolter 1998). In this work, combinations of phytochemicals and antibiotics were evaluated with respect to the prevention and control of Staphylococcus aureus biofilms. It may be expected that by combining antibiotics with an adjuvant, acting as biofilm inhibitor, as resistancemodifying agent, or even as a cell permeabilizer, the outcome would be an improved therapeutic benefit (Abreu et al. 2013). Further experiments were performed in order to understand the mode of action of these phytochemicals and whether the synergic combinations of phytochemicals and antibiotics were due to resistance modifying activity.

\section{Materials and methods}

\section{Bacteria and culture conditions}

S. aureus SA1199B, S. aureus RN4220 and S. aureus XU212, which overexpress the NorA, TetK and MsrA efflux pumps, respectively, were kindly provided by S. Gibbons (University College London, UCL) (Gibbons \& Udo 2000; Gibbons et al. 2003; Oluwatuyi et al. 2004; Smith et al. 2007). The collection strain S. aureus CECT 976 was included as a quality control strain. The strains were stored at $-80^{\circ} \mathrm{C}$. Prior use, they were transferred to a Mueller-Hinton (MH, Merck Millipore, Germany) agar plate grown overnight and inoculated in $\mathrm{MH}$ broth at $37^{\circ} \mathrm{C}$ and under agitation $(150 \mathrm{rpm})$. Bacterial susceptibility was assessed following the Clinical and Laboratory Standards Institute (CLSI 2003) guidelines as shown in Table 1.

\section{Preparation of antibiotics and phytochemicals}

Stock solutions of ciprofloxacin, erythromycin and tetracycline (Sigma, Sintra, Portugal) were prepared

Table 1. Characteristics of the S. aureus strains.

\begin{tabular}{|c|c|c|c|}
\hline Strains & Antibiotic & $\mathrm{MIC}\left(\mathrm{mg} \mathrm{I}^{-1}\right)$ & Description \\
\hline \multirow[t]{3}{*}{ CECT 976} & CIP & $1(S)$ & From the Spanish Type Culture \\
\hline & TET & $0.96(S)$ & Collection; no antibiotic \\
\hline & ERY & $0.24(S)$ & resistance described \\
\hline SA1199B & CIP & $128(\mathrm{R})$ & $\begin{array}{l}\text { Overexpresses NorA efflux } \\
\text { pump }\end{array}$ \\
\hline XU212 & TET & $128(R)$ & $\begin{array}{l}\text { Overexpresses the TetK efflux } \\
\text { pump }\end{array}$ \\
\hline RN4220 & ERY & $256(R)$ & $\begin{array}{l}\text { Contains plasmid pU5054 (that } \\
\text { carries the gene encoding the } \\
\text { MsrA efflux protein) }\end{array}$ \\
\hline
\end{tabular}

Notes: MIC were determined for each strain according to CLSI guidelines (CLSI 2003) and classified as resistant (R) or susceptible (S) to ciprofloxacin (CIP), tetracycline (TET) and erythromycin (ERY). (at $10 \mathrm{gl}^{-1}$ ) according to the manufacturer's recommendations. Reserpine, pyrrolidine, quinine, morin and quercetin (Sigma) were prepared in dimethyl sulfoxide (DMSO; Sigma-Aldrich). Stock concentrations were prepared at $10 \mathrm{~g}^{-1}$ for quinine and reserpine and $50 \mathrm{~g} \mathrm{l}^{-1}$ for morin, quercetin and pyrroldine. The compounds were stored at $-4^{\circ} \mathrm{C}$.

\section{Biofilm formation, prevention and control}

The minimal inhibitory concentration (MIC) of the antibiotics and phytochemicals were first determined against planktonic cells according to CLSI guidelines (CLSI 2003) and as described by Abreu et al. $(2014,2015)$. Antibiotics were applied at MIC, $10 \times$ MIC and $50 \times$ MIC against biofilms. The phytochemicals were found to have no antimicrobial activity for the concentrations tested (up to $1,500 \mathrm{mg} \mathrm{l}^{-1}$, data not shown). Consequently, the concentrations applied corresponded to the optimal concentrations previously found to potentiate the antibiotics against the tested bacteria in planktonic state: $100 \mathrm{mg} \mathrm{l}^{-1}$ for reserpine and quinine and $500 \mathrm{mg} \mathrm{l}^{-1}$ for pyrrolidine, quercetin and morin (Abreu et al. 2014, 2015).

Antibiotics and phytochemicals were tested individually and in combination in order to assess their ability to control biofilms and prevent their formation. Overnight cultures adjusted to a cell density of $10^{6}$ cells $\mathrm{ml}^{-1}$ were added to sterile 96-well polystyrene microtiter plates (Orange Scientific, Braine-l'Alleud, Belgium) to form biofilms during $24 \mathrm{~h}$ at $37^{\circ} \mathrm{C}$ and $150 \mathrm{rpm}$. Afterwards, the medium was removed and the biofilms were exposed to the antibiotics, phytochemicals and their combinations (at $5 \%\left(\mathrm{v} \mathrm{v}^{-1}\right)$ of the well for a final volume of $200 \mu \mathrm{l}^{-1}$ ), for $1 \mathrm{~h}$ at $37^{\circ} \mathrm{C}$ and $150 \mathrm{rpm}$. The same protocol was performed for an exposure time of $24 \mathrm{~h}$. These assays tested the effects of two exposure times in the control of established biofilms.

In order to assess the combinations towards the prevention of biofilm formation, overnight cell suspensions were added to microtiter plates along with antibiotics, phytochemicals and their combinations $\left(5 \% \mathrm{v} \mathrm{v}^{-1}\right.$ of the well). The plates were incubated for $24 \mathrm{~h}$ at $37^{\circ} \mathrm{C}$ and $150 \mathrm{rpm}$. After incubation, biofilms were scraped and diluted in saline solution $(0.85 \% \mathrm{NaCl})$. The numbers of colony forming units per unit of adhesion area $\left(\mathrm{CFU} \mathrm{cm} \mathrm{cm}^{-2}\right)$ were assessed in $\mathrm{MH}$ agar for both biofilm control and prevention experiments. The results are presented as a $\log _{10}$ CFU cm $\mathrm{cm}^{-2}$ reduction from the DMSO control.

A phytochemical-antibiotic synergy assay was performed according to Monzon et al. (2001). The combination was considered synergic when the $\log _{10}$ reduction CFU $\mathrm{cm}^{-2}$ caused by a combination was significantly higher $(p<0.05)$ than the sum of reductions by the 
individual treatments. An antagonistic combination was characterized when the $\log _{10}$ reduction in $\mathrm{CFU} \mathrm{cm}{ }^{-2}$ of the combination was significantly lower $(p<0.05)$ than that obtained with the more active product.

\section{Antibiotic adaptation assay}

An antibiotic adaptation assay was performed with S. aureus SA1199B growing with increasing subinhibitory concentrations of ciprofloxacin for 15 days, according to Figure 1. The most promising phytochemical-antibiotic synergy results were obtained with this strain, and therefore it was selected for the antibiotic adaptation assay aiming to understand whether the phytochemicals were effective in reversing bacterial resistance or avoiding the development of resistance due to prolonged exposure. S. aureus SA1199B was grown overnight in $\mathrm{MH}$ broth at $37^{\circ} \mathrm{C}$, adjusted to a cell density of $10^{6}$ cells $\mathrm{ml}^{-1}$ and incubated with ciprofloxacin at $1 / 32 \times \mathrm{MIC}\left(4 \mathrm{mg} \mathrm{l}^{-1}\right.$, phase 1) for $24 \mathrm{~h}$ (at $37^{\circ} \mathrm{C}$ and $150 \mathrm{rpm}$ agitation) in the presence of each phytochemical. After $24 \mathrm{~h}$, the bacterium was refreshed: centrifugation was performed at $3,999 \mathrm{~g}$ for $10 \mathrm{~min}$, the supernatant discarded, the pellet was washed twice and resuspended in $\mathrm{MH}$ broth with both molecules (at the same concentrations). This procedure was repeated after $48 \mathrm{~h}$. On the fourth day, after washing the cultures, the concentration of the antibiotic was increased to $1 / 16 \times \operatorname{MIC}\left(8 \mathrm{mgl}^{-1}\right.$, phase 2$)$, and consecutively, for a total of 15 days, until a final concentration of $1 / 2 \times$ MIC was reached. Controls were performed in the absence of phytochemicals or ciprofloxacin and with DMSO (5\% $\mathrm{v} \mathrm{v}^{-1}$ ). Bacterial samples were taken every three days, washed as previously described and susceptibility profiles of bacterial populations to ciprofloxacin were evaluated by the disk diffusion method according to CLSI guidelines (CLSI 2003). The final population grown in the presence of only ciprofloxacin (named SA1199B(r)) was recovered after 15 days, washed and stocks were prepared for further

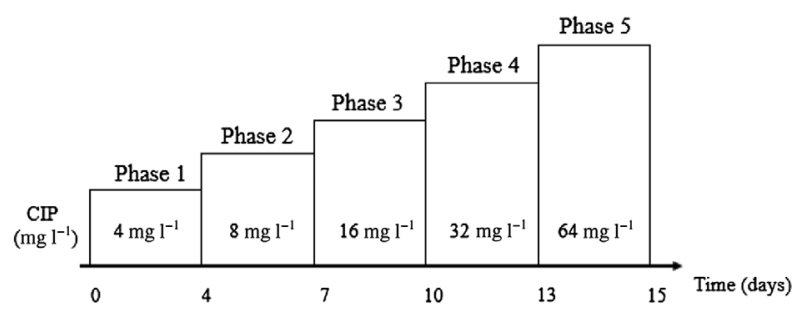

Figure 1. Scheme of ciprofloxacin treatment applied to $S$. aureus SA1199B for 15 days in order to assess bacterial adaptation. Bacterial cultures were incubated with defined subinhibitory concentrations of ciprofloxacin increasing every three days (from $1 / 32 \times$ MIC to $1 / 2 \times$ MIC) for a total of 15 days. Bacterial susceptibility to ciprofloxacin was determined in the end of each cycle by disk diffusion method (CLSI 2003). experiments to assess efflux pump inhibition with ethidium bromide (EtBr). Triplicates of each combination were performed.

\section{Disk diffusion method}

Bacterial suspensions were adjusted to $0.5 \mathrm{McF}$ arland standards and seeded over hardened $\mathrm{MH}$ agar in Petri dishes using a sterilized cotton swab. Sterile blank disks (6 mm diameter; Oxoid, Madrid, Spain) were placed on the agar plate seeded with the respective bacteria. A volume of $10 \mu \mathrm{l}$ of ciprofloxacin prepared according to CLSI (2003) (ciprofloxacin $-5 \mu$ disk $^{-1}$ ) was added to the blank disks. Disks with $10 \mu \mathrm{l}$ of DMSO were used as negative control. The plates were incubated at $37^{\circ} \mathrm{C}$ for $24 \mathrm{~h}$. After incubation each inhibition zone diameter (IZD) was recorded and antibiotic susceptibility was analyzed according to CLSI guidelines (CLSI 2003). No inhibition zone was obtained with DMSO (data not shown). All tests were performed in triplicate.

\section{Ethidium bromide accumulation assay}

Ethidium bromide (EtBr) accumulation was tested in order to assess the putative action of phytochemicals as NorA inhibitors. First, the MIC of EtBr (prepared in a stock of $10 \mathrm{~g} \mathrm{l}^{-1}$ ) was first determined according to CLSI guidelines (CLSI 2003) and described by Abreu et al. (2014, 2015). The detection of EtBr accumulation by $S$. aureus strains was performed using a fluorometric method according to Rodrigues et al. (2013) and Jin et al. (2011). Briefly, bacteria were grown in $\mathrm{MH}$ broth at $37^{\circ} \mathrm{C}$ until mid-log phase $\left(\mathrm{OD}_{600}\right.$ of 0.6 to 0.7$)$. Bacterial suspensions were centrifuged at $3,999 \mathrm{~g}$ for $10 \mathrm{~min}$, the supernatant was discarded, the pellet was washed in phosphate buffered saline (PBS; $\mathrm{pH}$ 7.4), and bacterial suspension adjusted to $10^{8} \mathrm{CFU} \mathrm{ml}{ }^{-1}$ with PBS. Aliquots of $100 \mu \mathrm{l}$ of the bacterial suspensions were transferred to wells of a 96-well plate containing serial dilutions of $\mathrm{EtBr}$ at concentrations ranging from 80 to $0.06 \mathrm{mg} \mathrm{l}^{-1}$. In order to assess the effect of phytochemicals on EtBr accumulation, EtBr (at $1 \frac{1}{2} \mathrm{MIC}$, in order not to compromise the bacterial viability) was applied in the absence or presence of each phytochemical: reserpine and quinine at $100 \mathrm{mg} \mathrm{l}^{-1}$; pyrrolidine, quercetin and morin at $500 \mathrm{mgl}^{-1}$ (Abreu et al. 2014, 2015). The negative control was performed with $5 \%\left(\mathrm{v} \mathrm{v}^{-1}\right)$ DMSO. Also, controls for each phytochemical with $\mathrm{EtBr}$ in $\mathrm{PBS}$ were performed in order to detect possible fluorescence emitted by the products themselves. Fluorescence was acquired every $1 \mathrm{~min}$ for $60 \mathrm{~min}$ at $37^{\circ} \mathrm{C}$ in a microplate reader (Spectramax M2e, Molecular Devices, Inc., Sunnyvale, CA, USA) using 530 and $590 \mathrm{~nm}$ as excitation and detection wavelengths, respectively. 


\section{Statistical analysis}

The results were analyzed by Student's $t$-test using SPSS (Statistical Package for the Social Sciences) version 19.0 (IBM Corp., Armonk, NY, USA). Statistical calculations were based on a confidence level 95\% $(p<0.05)$ which was considered statistically significant. All $p$-values reported were two-tailed.

\section{Results and discussion}

Biofilms are recognized for their insusceptibility to current therapeutic approaches (Smith 2005; Römling \& Balsalobre 2012). This is due to the different characteristics of biofilm cells compared to their planktonic counterparts (Simões et al. 2009). For instance, S. aureus in biofilms expresses a different set of genes such as ica types, and bap and agr types, with an increased potential to induce the development of recurrent infections (GogoiTiwari et al. 2015). Therefore, new biofilm control strategies are required. Phytochemicals have been extensively studied as antibacterial products and, more recently, as potentiators/adjuvants of antibiotics (Markham et al. 1999; Abreu et al. 2012). However, few data can be found on their effects against biofilms, even though most infections are biofilm-related. The ability of phytochemicals and antibiotics to control $24 \mathrm{~h}$ old biofilms formed in sterile 96-well polystyrene microtiter plates within 1 and $24 \mathrm{~h}$ of exposure was evaluated. Antibiotics were first applied alone at MIC, $10 \times \mathrm{MIC}$ and $50 \times \mathrm{MIC}$. As no significant differences $(p>0.05)$ in biofilm $\log _{10} \mathrm{CFU} \mathrm{cm} \mathrm{cm}^{-2}$ reduction were obtained (data not shown), the combinations were
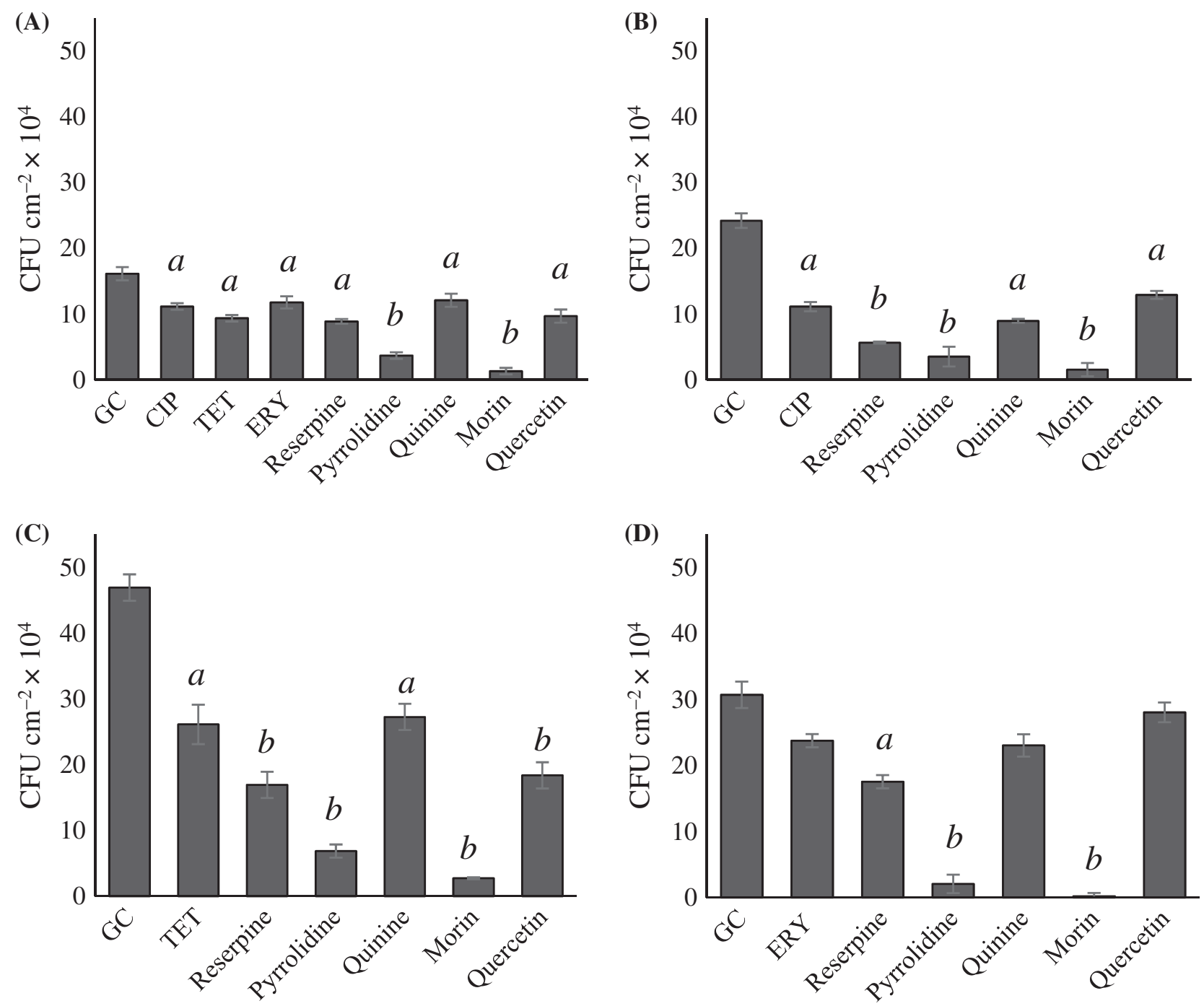

Figure 2. CFU cm ${ }^{-2}$ of biofilms after exposure to antibiotics and phytochemicals for $1 \mathrm{~h}$ : S. aureus CECT976 (A), SA1199B (B), XU212 (C) and RN4220 (D). Strains SA1199B, XU212 and RN4220 were only exposed to the antibiotics to which they are resistant: CIP, TET and ERY, respectively. Antibiotics were applied at MIC; reserpine and quinine were applied at $100 \mathrm{mg} \mathrm{I}^{-1}$; pyrrolidine, morin and quercetin were applied at $500 \mathrm{mg} \mathrm{l}^{-1}$. $a$, when statistically lower than GC $(p<0.05) ; b$, when statistically lower than GC and the antibiotics $(p<0.05)$. GC, growth control (5\%, v v $\mathrm{v}^{-1}$ DMSO); CIP, ciprofloxacin; TET, tetracycline; ERY, erythromycin. 
(A)

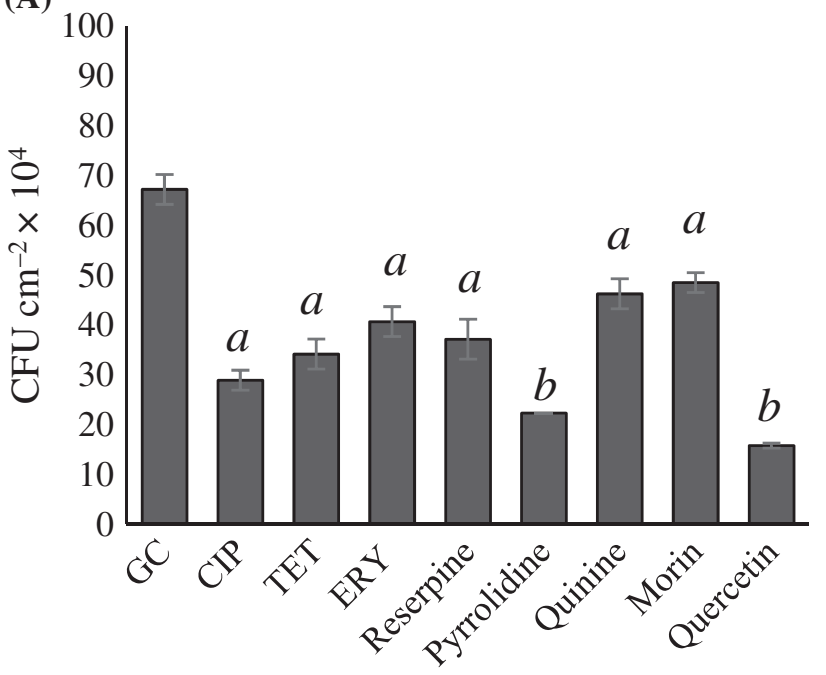

(C)

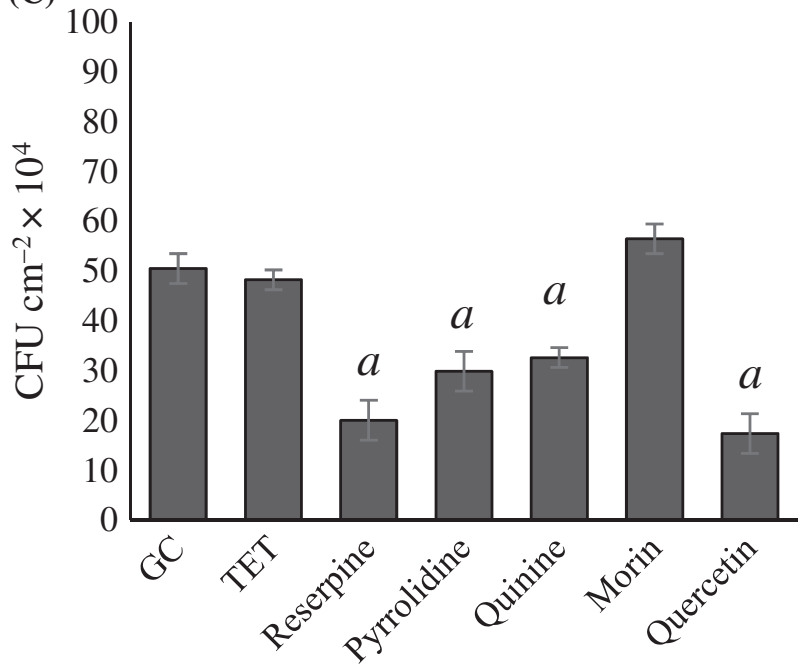

(B)

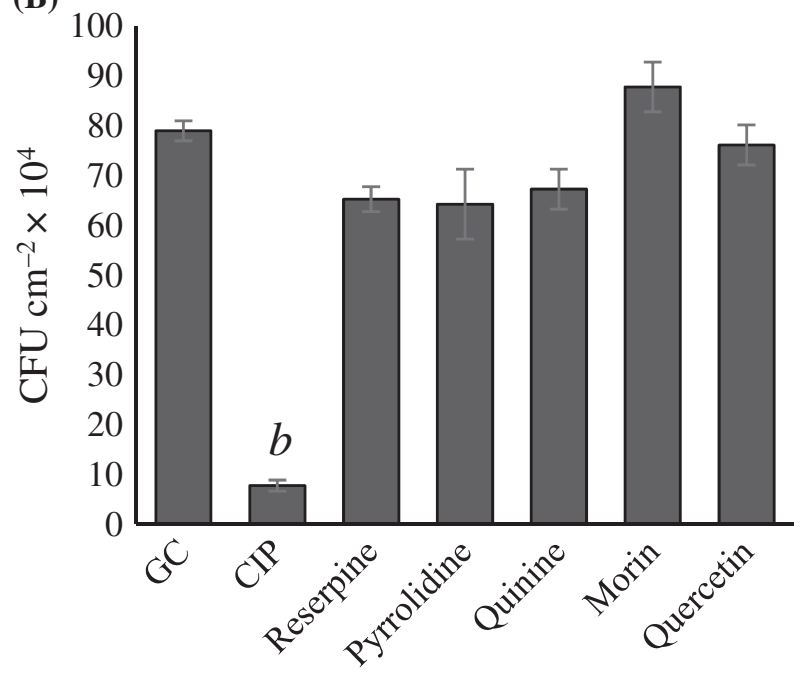

(D)

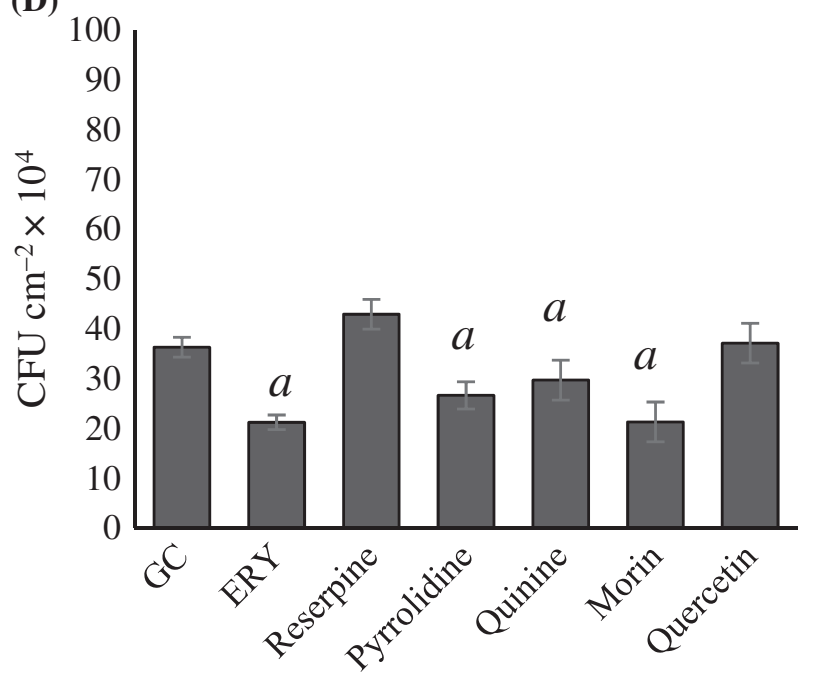

Figure 3. CFU cm $\mathrm{cm}^{-2}$ of biofilms after exposure to antibiotics and phytochemicals for $24 \mathrm{~h}$. S. aureus CECT976 (A), SA1199B (B), XU212 (C) and RN4220 (D). Strains SA1199B, XU212 and RN4220 were only exposed to the antibiotics to which they are resistant: CIP, TET and ERY, respectively. Antibiotics were applied at MIC; reserpine and quinine were applied at $100 \mathrm{mg} \mathrm{l}^{-1}$; pyrrolidine, morin and quercetin were applied at $500 \mathrm{mg} \mathrm{I}^{-1}$. $a$, when statistically lower than $\mathrm{GC}(p<0.05)$; $b$, when statistically lower than $\mathrm{GC}$ and the antibiotics $(p<0.05)$. GC, growth control (5\%, $\left.\mathrm{v} \mathrm{v}^{-1} \mathrm{DMSO}\right)$; CIP, ciprofloxacin; TET, tetracycline; ERY, erythromycin.

performed with antibiotics at their MIC. Figures 2 and 3

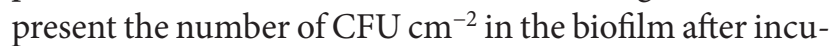
bation with antibiotics at their MIC and phytochemicals individually for 1 and $24 \mathrm{~h}$, respectively. Phytochemicals were applied at subinhibitory concentrations that were previously found to cause antibiotic-potentiation (Abreu et al. 2014, 2015). Morin at $500 \mathrm{mg} \mathrm{l}^{-1}$ applied for $1 \mathrm{~h}$ (Figure 2) caused the highest CFU reductions $\left(\log _{10} \mathrm{CFU} \mathrm{cm} \mathrm{cm}^{-2}\right.$ reductions of $1.2-2.1$ for all strains), followed by pyrrolidine (at $500 \mathrm{mg} \mathrm{l}^{-1}, \log _{10} \mathrm{CFU} \mathrm{cm}^{-2}$ reductions of $\left.0.7-1.1\right)$. These reductions were higher $(p<0.05)$ than those obtained with antibiotics applied at MIC $\left(\log _{10} \mathrm{CFU} \mathrm{cm} \mathrm{cm}^{-2}\right.$ reductions of $0.08-0.4)$. These results proposed that the selected phytochemicals caused biofilm disruption as they did not show antimicrobial activity by themselves. However, morin and pyrrolidine were not effective $(p<0.05)$ in disturbing biofilms for a $24 \mathrm{~h}$ exposure period, for which the maximal $\log _{10} \mathrm{CFU} \mathrm{cm} \mathrm{cm}^{-2}$ reductions were 0.3 and 0.5 , respectively (Figure 3 ). The decreased susceptibility to prolonged exposure periods was generally observed for almost all the strains. This is probably due to the effects of longer incubation periods. The fast growing cells will die readily when exposed to the antibiotics but the dormant cells fraction can survive and replicate (Shafahi \& Vafai 2010). The exception was verified with strain SA1199B when exposed to ciprofloxacin, where the $\log _{10} \mathrm{CFU} \mathrm{cm}{ }^{-2}$ reduction increased with the longer exposure from 0.4 to 1.1 .

Additionally, in order to assess the ability of the phytochemicals to prevent bacterial adhesion and biofilm 
(A)

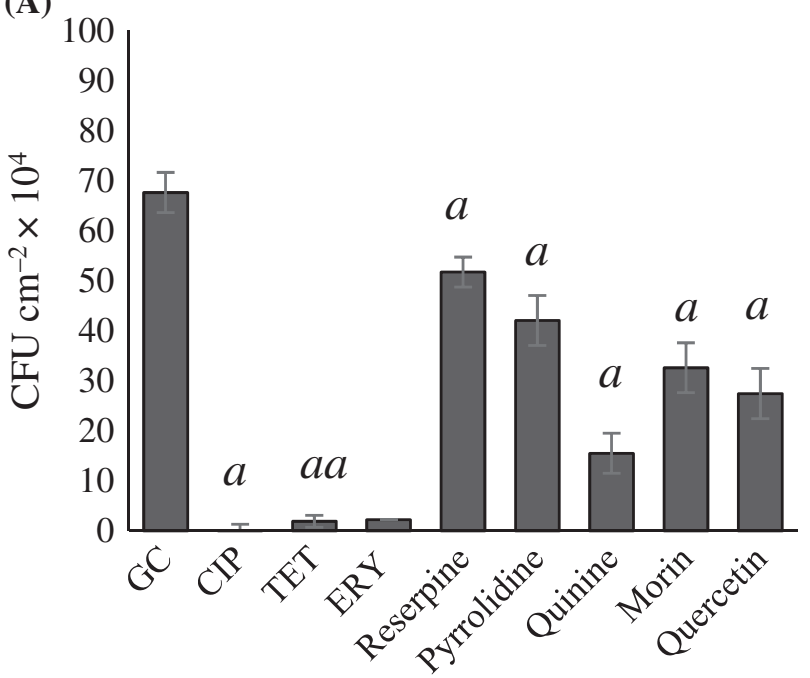

(C)

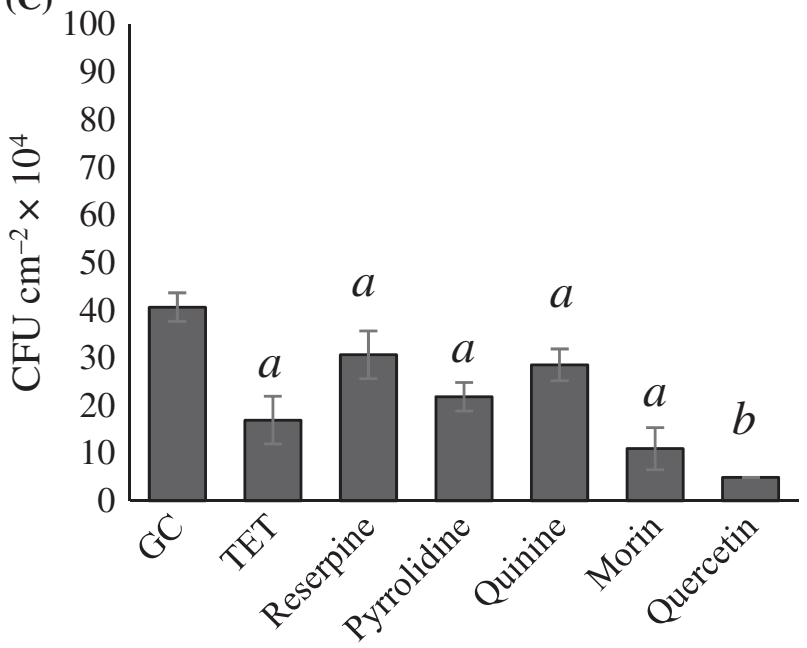

(B)

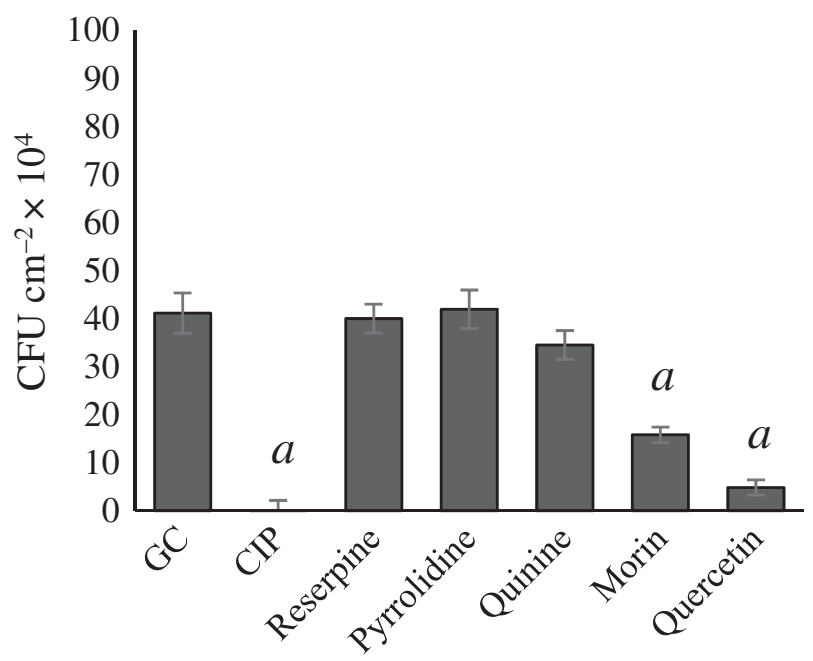

(D)

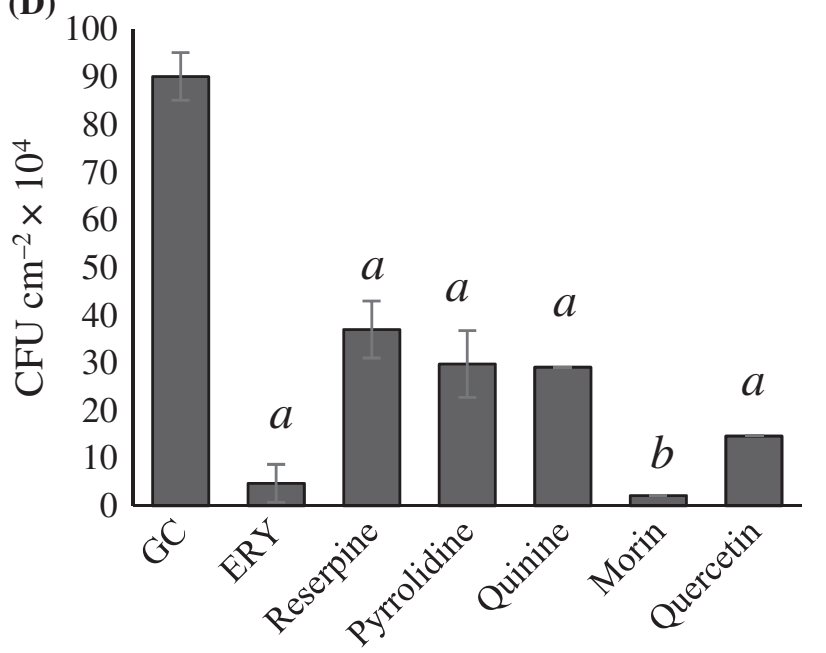

Figure 4. CFU cm${ }^{-2}$ of S. aureus CECT976 (A), SA1199B (B), XU212 (C) and RN4220 (D) biofilms after $24 \mathrm{~h}$ growth in the presence of antibiotics and phytochemicals. Strains SA1199B, XU212 and RN4220 strains were only exposed to the antibiotics to which they are resistant to: CIP, TET and ERY, respectively. Antibiotics were applied at MIC; reserpine and quinine were applied at $100 \mathrm{mg} \mathrm{l}^{-1}$; pyrrolidine, morin and quercetin were applied at $500 \mathrm{mgl}^{-1}$. $a$, when statistically lower than $\mathrm{GC}(p<0.05) ; b$, when statistically lower than $\mathrm{GC}$ and the antibiotics $(p<0.05)$. GC, growth control $\left(5 \%, v^{-1}\right.$ DMSO); CIP, ciprofloxacin; TET, tetracycline; ERY, erythromycin.

formation, tests with sessile cells were performed in the presence of the phytochemicals for $24 \mathrm{~h}$. Figure 4 pre-

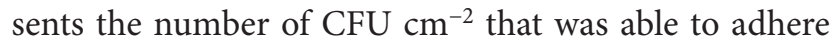
to polystyrene when grown in the presence of the antibiotics and phytochemicals for $24 \mathrm{~h}$. All antibiotics (at MIC) caused significant prevention of biofilm formation - a reduced number of CFU $\mathrm{cm}^{-2}$ compared to growth control $(p<0.05)$. Morin was able to reduce biofilm formation of all strains $(p<0.05)$, especially of RN4220 (1.4 $\log _{10} \mathrm{CFU} \mathrm{cm} \mathrm{c}^{-2}$ reduction). Additionally, quercetin at $500 \mathrm{mg} \mathrm{l}^{-1}$ also had a considerable effect in preventing biofilm formation $(p<0.05)$, particularly of strains SA1199B and XU212 ( 1 $\log _{10}$ CFU cm ${ }^{-2}$ reduction). Pyrrolidine was unable to prevent biofilm formation, as it did not affect biofilm removal when applied for $24 \mathrm{~h}$, despite showing significant effects when applied for $1 \mathrm{~h}$ $(p<0.05)$. No antibiotic or phytochemical caused total biofilm control or prevention. This reinforces the higher tolerance of biofilm cells compared to their planktonic counterparts. Studies report that even cells that are merely adhered to a surface have more resistant phenotypes (Bridier et al. 2011). However, it seems that among all the phytochemicals, morin was particularly effective in controlling (within $1 \mathrm{~h}$ of incubation) and inhibiting biofilm formation. Morin can therefore be added to the reduced list of phytochemicals with potential to interfere with the process of biofilm formation and development (Simões et al. 2009).

Table 2 presents the $\log _{10} \mathrm{CFU} \mathrm{cm} \mathrm{cm}^{-2}$ reductions caused by the phytochemical-antibiotic combinations applied to all strains. The maximum CFU reduction was obtained after $24 \mathrm{~h}$ exposure to the synergic combination of ciprofloxacin and quinine (2.1 $\log _{10} \mathrm{CFU} \mathrm{\textrm {cm } ^ { - 2 }}$ reduction) against SA1199B biofilms. Additionally, a combination of 
Table 2. $\log _{10}$ CFU cm$~^{-2}$ reductions after biofilm exposure to antibiotic-phytochemical combinations.

\begin{tabular}{|c|c|c|c|c|c|c|c|c|c|c|c|c|c|c|c|c|}
\hline \multirow[b]{3}{*}{ Strains } & \multirow[b]{3}{*}{ Antib. } & \multicolumn{15}{|c|}{$\log _{10} \mathrm{CFU} \mathrm{cm} \mathrm{cm}^{-2}$ reductions } \\
\hline & & \multicolumn{5}{|c|}{ A - Biofilm control (1 h) } & \multicolumn{5}{|c|}{ B - Biofilm control (24 h) } & \multicolumn{5}{|c|}{ C-Biofilm prevention } \\
\hline & & Res & Pyr & Qui & Mor & Querc & Res & Pyr & Qui & Mor & Querc & Res & Pyr & Qui & Mor & Querc \\
\hline \multirow[t]{3}{*}{ CECT 976} & CIP & 0.29 & 0.91 & 0.36 & 1.29 & 0.45 & 0.33 & 0.52 & 0.48 & $0.05(\mathrm{~A})$ & $0.03(\mathrm{~A})$ & 3.21 & 3.34 & 3.51 & $1.42(\mathrm{~A})$ & $1.13(\mathrm{~A})$ \\
\hline & TET & 0.49 & 0.81 & 0.42 & 0.99 & 0.05 (A) & 0.28 & 0.24 (A) & 0.25 & $0.04(\mathrm{~A})$ & 0.04 (A) & 1.43 & $0.97(\mathrm{~A})$ & 1.41 & 1.33 & $1.06(\mathrm{~A})$ \\
\hline & ERY & 0.28 & $1.44(\mathrm{~S})$ & 0.26 & $0.64(\mathrm{~A})$ & 0.28 & 0.49 & 0.47 & 0.48 & 0.18 & $0.28(\mathrm{~A})$ & 1.51 & $2.09(\mathrm{~S})$ & 1.50 & 1.17 & 1.18 \\
\hline SA1199B & CIP & 0.37 & 1.10 & 0.53 & $0.98(\mathrm{~A})$ & 0.57 & $1.30(\mathrm{~S})$ & $1.71(\mathrm{~S})$ & $2.10(\mathrm{~S})$ & 1.05 & 0.92 & $3.52(\mathrm{~S})$ & 2.7 & 3.05 & 3.43 & 2.11 \\
\hline XU212 & TET & 0.33 & 0.93 & 0.29 & $0.92(\mathrm{~A})$ & 0.37 & 0.23 & 0.16 & 0.22 & $0.33(\mathrm{~S})$ & 0.11 & $0.70(S)$ & $1.55(\mathrm{~S})$ & 0.48 & $1.12(\mathrm{~S})$ & 1.16 \\
\hline RN4220 & ERY & 0.01 & 1.08 & $0.24(\mathrm{~S})$ & $1.03(\mathrm{~A})$ & $0.47(\mathrm{~S})$ & 0.36 & 0.39 & 0.49 & 0.29 & $0.05(\mathrm{~A})$ & 1.08 & 1.03 & 1.07 & 1.26 & 0.84 \\
\hline
\end{tabular}

A - biofilm exposure to antibiotics and phytochemicals for $1 \mathrm{~h}$; B - biofilm exposure to antibiotics and phytochemicals for $24 \mathrm{~h} ; \mathrm{C}-$ biofilm grown in the presence of antibiotics and phytochemical/biofilm prevention. The combination was considered synergic (S) when a $\log _{10} \mathrm{CFU} \mathrm{cm}^{-2}$ reduction by the combination was significantly higher $(p<0.05)$ than the sum of $\log _{10}$ CFU cm${ }^{-2}$ reductions in individual treatments (Monzon et al. 2001). An antagonistic (A) combination was obtained when the $\log _{10} \mathrm{CFU} \mathrm{cm} \mathrm{cm}^{-2}$ reduction in the combination was significantly lower $(p<0.05)$ than that obtained with the most effective product. Bold values represent synergic interactions with a $\log _{10} \mathrm{CFU} \mathrm{cm}^{-2}$ reduction $\geq 1.0$.

*Pyr, Mor, Querc: $500 \mathrm{mg} \mathrm{l}^{-1}$; Res, Quin: $100 \mathrm{mg} \mathrm{l}^{-1}$. CIP, ciprofloxacin; TET, tetracycline; ERY, erythromycin; Res, reserpine; Pyr, pyrrolidine; Quin, quinine, Mor, morin; Querc, quercetin.

ciprofloxacin with reserpine, also considered synergic, was the most efficient in preventing biofilm formation (a 3.5 $\log _{10}$ CFU cm$~^{-2}$ reduction) of strain SA1199B. Other synergic antibiotic-phytochemical combinations were found, with the following causing $\geq 1 \log _{10} \mathrm{CFU} \mathrm{cm}{ }^{-2}$ reduction: ciprofloxacin combined with pyrrolidine and reserpine (a $\log _{10}$ CFU cm$~^{-2}$ reduction of 1.7 and 1.3 , respectively) to control SA1199B biofilms exposed for $24 \mathrm{~h}$; erythromycin combined with pyrrolidine to control biofilms of CECT976 exposed for $1 \mathrm{~h}$ (a $1.4 \log _{10} \mathrm{CFU} \mathrm{cm}{ }^{-2}$ reduction) and also to prevent their formation (a $2.1 \log _{10} \mathrm{CFU} \mathrm{cm} \mathrm{cm}^{-2}$ reduction); and tetracycline combined with pyrrolidine and morin to prevent biofilm formation of XU212 (a $\log _{10}$ CFU cm$~^{-2}$ reduction of 1.6 and 1.1, respectively). The majority of these synergic results corroborate previous studies with planktonic cells (Abreu et al. 2014, 2015). Some antagonistic results were obtained, especially for combinations involving the phenolic compounds. It seems that the presence of antibiotics disturbs the activity of morin, which was found to be effective when applied individually for $1 \mathrm{~h}$. Indeed, biofilms facilitate the spread of antibiotic resistance by promoting horizontal gene transfer and cells can switch to more tolerant phenotypes upon environmental stress (Fux et al. 2005). Antagonistic combinations were also found with quercetin when combined with antibiotics mainly against CECT976 biofilms. Other discrepancies in the effects against the diverse strains were found, such as the fact that combinations of tetracycline with morin and tetracycline with pyrrolidine were synergic against XU212 but antagonistic against CECT976 in a biofilm control for $24 \mathrm{~h}$ and biofilm prevention, respectively. This strain-dependent susceptibility can be related to the impact of combined stresses on their susceptibility/ resistance patterns and it would need a more integrated approach in order to be fully understood. Antibioticmediated interactions may trigger multicellular behavior in bacteria, which makes it impossible to predict cell responses. The remaining combinations tested had indifferent effects on biofilm prevention and control.

Since most synergic interactions were obtained against strain SA1199B (a NorA overexpressing strain), a further experiment was conducted to induce adaptation of SA1199B to ciprofloxacin. The phytochemicals were also used to understand their effects in reversing bacterial adaptation to ciprofloxacin after long exposure times. Figure 5 shows the results obtained in the adaptation assay with SA1199B to ciprofloxacin (the treatment was performed as previously indicated in Figure 1). By growing this strain with subinhibitory concentrations of ciprofloxacin (control assay) it was possible to observe a reduction in the IZD until day 9 (phase 3 ), and then no IZD was detected (phases 4 and 5), indicating that bacteria became more resistant to ciprofloxacin. Biological responses induced in bacteria when antibiotics are applied at subinhibitory concentrations can affect various cellular responses or alter gene expression leading to different adaptive responses impacting antibiotic resistance/ tolerance (Kaplan et al. 2012; Bernier \& Surette 2013). A potential increased NorA overexpression could explain the improved tolerance to ciprofloxacin observed by strain SA1199B. In phases 2 and 3, it was possible to observe that the populations growing in the presence of all phytochemicals were more susceptible, since IZD promoted by ciprofloxacin were significantly higher $(p<0.05)$ than IZD obtained when bacteria were growing only in the presence of ciprofloxacin. According to CLSI guidelines (CLSI 2003) IZD obtained in phase 3 allows characterization of the bacterial cultures as susceptible to ciprofloxacin. This susceptibility was observed earlier for quercetin growing-population (in phase 1). This means that until day 9 , all the phytochemicals were able to reverse the bacterial resistance mechanisms. However, by increasing ciprofloxacin concentrations to $1 / 4$ and $1 / 2$ MIC (phases 4 and 5, respectively), all populations were resistant to 


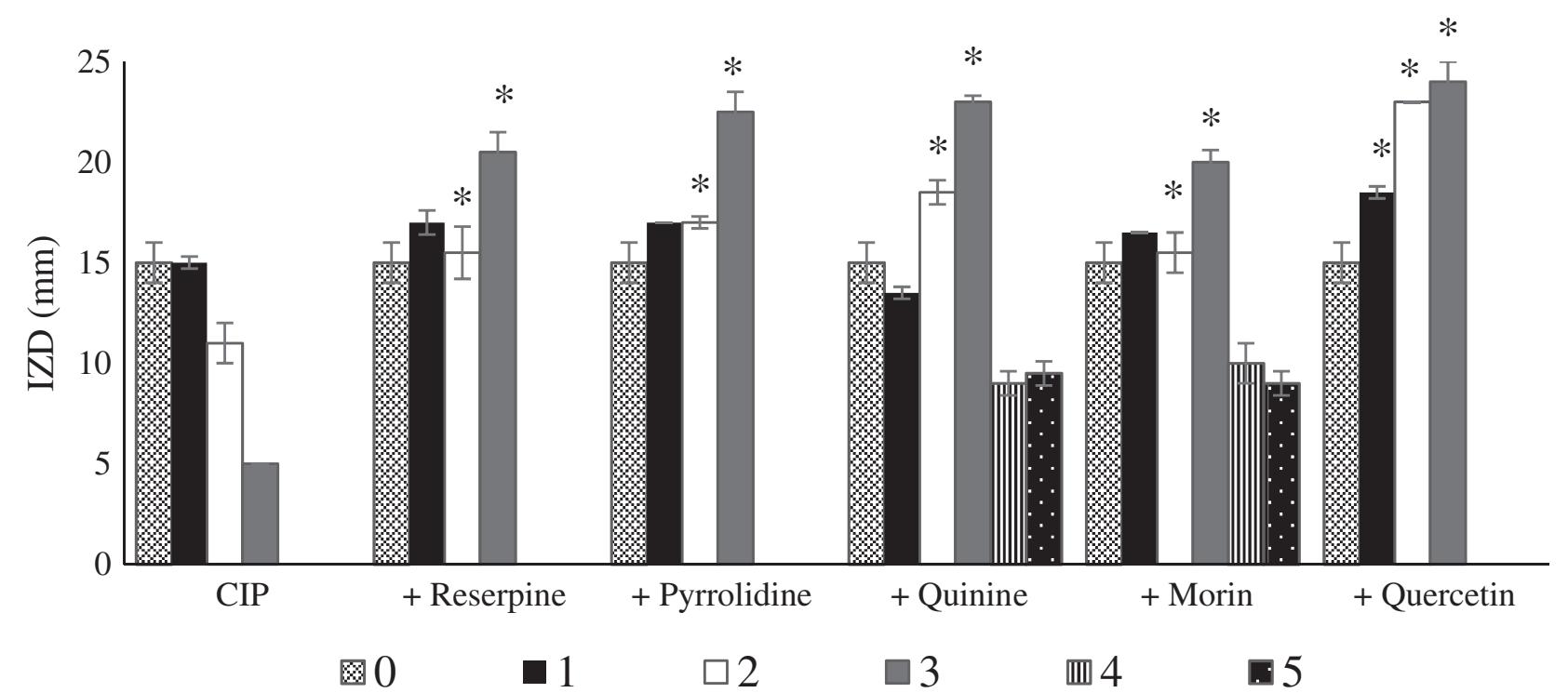

Figure 5. Inhibition zone diameter (IZD) promoted by ciprofloxacin against S. aureus SA1199B grown in the presence of increasing subinhibitory concentrations of ciprofloxacin (CIP) alone and in the presence of phytochemicals. Reserpine and quinine were applied at $100 \mathrm{mg} \mathrm{l}^{-1}$; pyrrolidine, morin and quercetin at $500 \mathrm{mg} \mathrm{l}^{-1}$. Results are given for the five different phases of this assay by increasing ciprofloxacin concentrations every three days (from 1/32 MIC to $1 / 2 \mathrm{MIC}$ ) over a total of 15 days, according to Figure 1 . Bars with $\left(^{*}\right.$ ) presented significantly higher inhibition zone diameters $(p<0.05)$ compared to the ciprofloxacin control population, for each phase.

ciprofloxacin similar to the control (no IZD detected), with the exception of bacteria growing in the presence of quinine and morin. The results indicate that both phytochemicals were successful in preventing tolerance to ciprofloxacin by strain SA1199B $(p<0.05)$.

The potential of the phytochemicals to inhibit NorA was tested using $\mathrm{EtBr}$, a substrate widely applied for detecting efflux activity in S. aureus strains (Costa et al. 2013). EtBr form complexes with double stranded DNA and RNA by intercalating between base pairs (Walberg et al. 1999). Several products, such as reserpine, behave as if they inhibit efflux pumps and hence have become known EPI (Holler et al. 2012). Accumulation of $\mathrm{EtBr}$ inside the bacterial cells can be increased in the presence of an EPI (Mullin et al. 2004; Holler et al. 2012) and can be measured fluorometrically in SA1199B cells due to the retention of fluorescence over time. Also, in order to understand if overexpression of NorA is the reason for the increased tolerance of bacterial cells growing with ciprofloxacin for 15 days, this population, named SA1199B(r), was included in the experiments. The susceptible strain CECT976 was also tested as negative control. The MIC of EtBr was first determined for each strain: $5 \mathrm{mg} \mathrm{l}^{-1}$ for CECT976 and $40 \mathrm{mg} \mathrm{l}^{-1}$ for SA1199B and SA1199B(r). Due to the good sensitivity of the fluorometric method, the demonstration of the effects of reserpine on the accumulation of EtBr on strain SA1199B over time was readily made. Figure 6A shows the comparison between $\mathrm{EtBr}$ accumulation in strains CECT976, SA1199B and SA1199B(r). CECT976 accumulated more EtBr contrarily to SA1199B and SA1199B(r), both overexpressing NorA. There were no significant differences between accumulation by SA1199B and SA1199B(r) ( $p>0.05)$, suggesting that the higher resistance of this strain to ciprofloxacin may be due to the expression of resistance mechanisms other than overexpression of NorA efflux pump. Figure 6B shows the effect of several concentrations of reserpine on EtBr accumulation. Reserpine at $20 \mathrm{mg} \mathrm{l}^{-1}$ is usually used as reference (Schmitz et al. 1998; Couto et al. 2008). Figure 6C shows the accumulation of EtBr by SA1199B in the presence of the phytochemicals. Quercetin (at $500 \mathrm{mg} \mathrm{l}^{-1}$ ) showed the best accumulation results $(p<0.05)$. Quinine (at $100 \mathrm{mg} \mathrm{l}^{-1}$ ) also improved EtBr accumulation $(p<0.05)$, suggesting that this compound inhibited the NorA efflux pump, apparently inducing higher tolerance of SA1199B to ciprofloxacin. Morin (at $500 \mathrm{mgl}^{-1}$ ) had no effect on $\mathrm{EtBr}$ accumulation, but it was able to prevent bacterial adaptation to ciprofloxacin, suggesting that this product is apparently involved in the inhibition of other mechanism, excluding the NorA efflux pump. Interestingly, the difference in the structures between morin and quercetin is that the first is $2^{\prime}, 4^{\prime}$-dihydroxylated in B ring while the second is $3^{\prime}, 4^{\prime}$-dyhydroxylated. However, it is already known that different substitutions on phenolic rings can promote significantly different activities (Cushnie \& Lamb 2005; Kumar \& Pandey 2013). Indeed, Tsuchiya et al. (1996) indicated that 2',4'- or 2',6'-dihydroxylation of the B ring and 5,7-dihydroxylation of the A ring in the flavanone structure was important for anti-MRSA activity. Previous findings using flavonols, such as fisetin, quercetin, and kaempferol described their anti-biofilm activity against $S$. aureus (Lee et al. 2013). In addition, it was found previously that several 
(A)

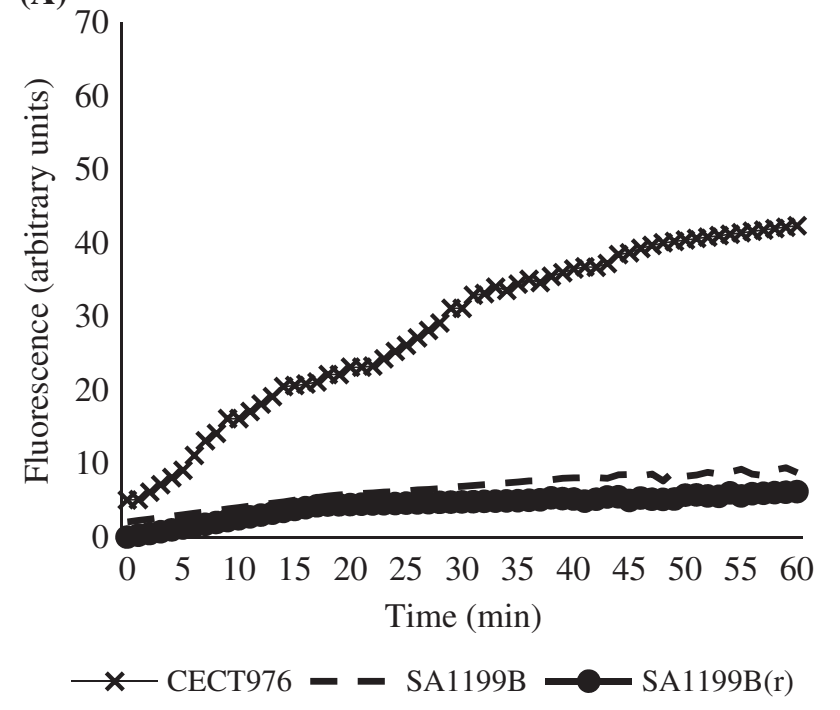

(B)
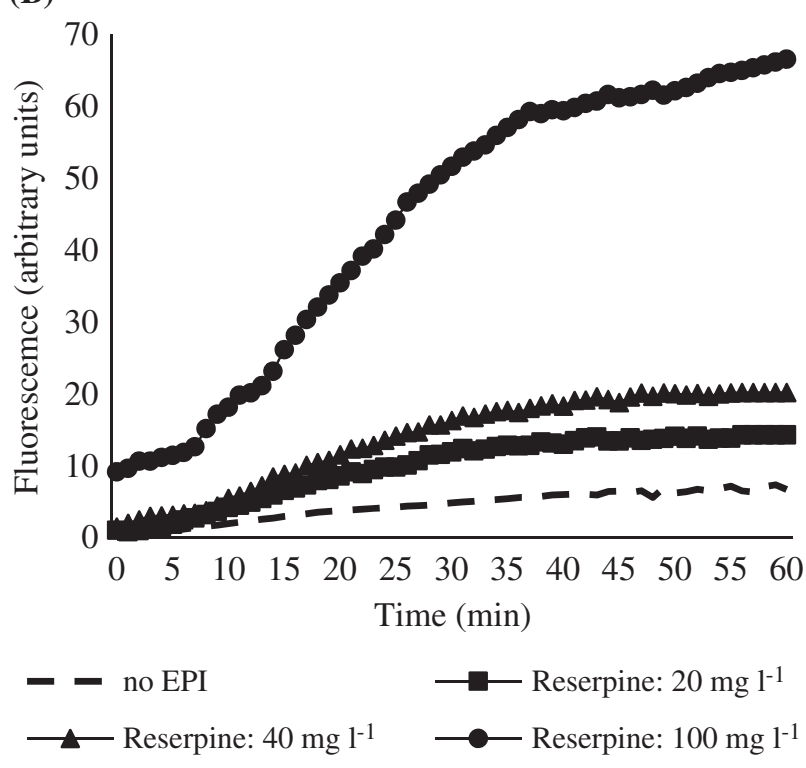

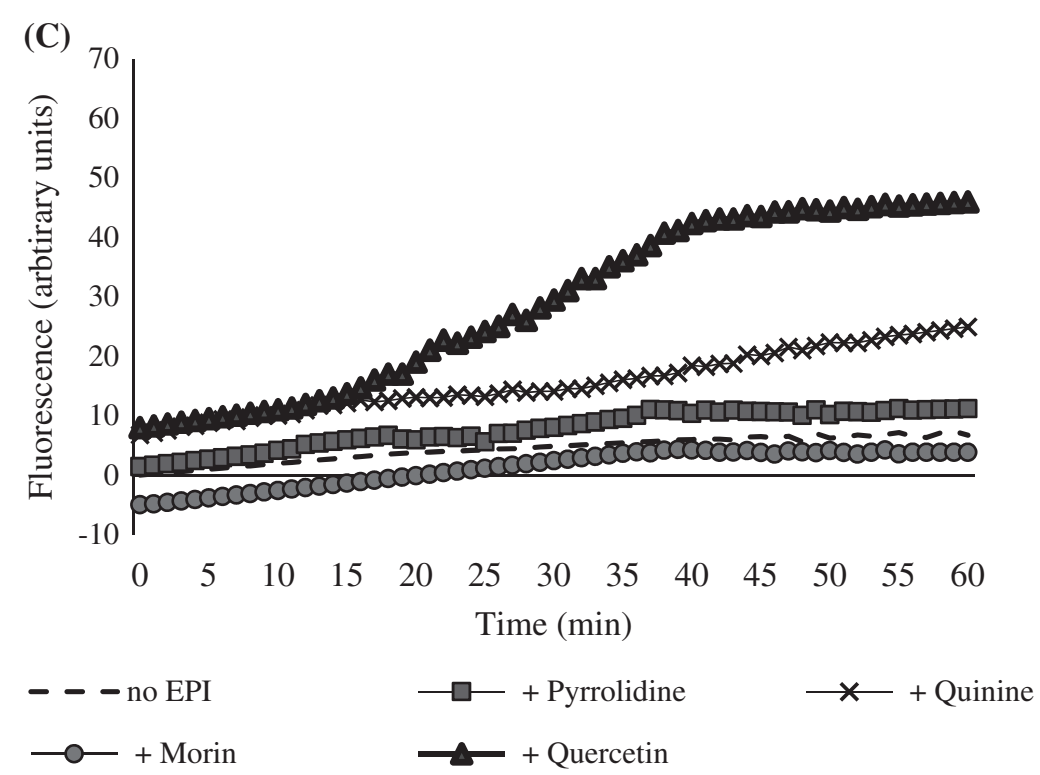

Figure 6. Fluorescence as a measure of EtBr accumulation. (A) EtBr accumulation in S. aureus CECT976, SA1199B and SA1199B(r); (B) effects of reserpine at 20,40 and $100 \mathrm{mg} \mathrm{l}^{-1}$ on $\mathrm{EtBr}$ accumulation; $(\mathrm{C})$ effects of phytochemicals on $\mathrm{EtBr}$ accumulation in $\mathrm{S}$. aureus SA1199B. The bacteria were loaded with EtBr at $1 / 2 \mathrm{MIC}$ in the presence of different phytochemicals for a period of $1 \mathrm{~h}$ at $37^{\circ} \mathrm{C}$. Mean values of three replicates are shown.

flavonoids, particularly quercetin, reduced hemolysis by S. aureus which would reduce its virulence and ability to form biofilms (Caiazza \& O’Toole 2003). Pyrrolidine did not improve $\mathrm{EtBr}$ accumulation neither was able to avoid or increase resistant of SA1199B strain $(p>0.05)$. However, it caused biofilm removal when applied for $1 \mathrm{~h}$.

Over the last decade there has been a resurgence of interest in the search for products that will restore the activity of licensed antimicrobial agents (Abreu et al. 2012). The prospects of finding useful plant-derived products are enormous. Many resistant mechanisms to antimicrobials, such as the ability to pump antibiotics out of cells, are shared between clinical and environmental bacteria (Wright 2010). Therefore, products that interfere with efflux of active inhibitors from the cell or other resistance mechanisms may be easily found in nature. Studies on plants allowed the discovery of interesting efflux pump inhibitors. This is an attractive strategy for the design of novel therapeutic approaches. With this study, known phytochemicals are highlighted for their important activities in co-therapies with known antibiotics against S. aureus biofilms.

In conclusion, despite being structurally different and presenting diverse activities, all the phytochemicals 
tested showed interesting results, highlighting the use of these substances as antibiotic adjuvants and resistance modifying agents for antimicrobial therapy against planktonic and sessile $S$. aureus. Morin applied for $1 \mathrm{~h}$ showed the best biofilm reduction and significantly inhibited biofilm formation of all the strains tested. Interestingly, morin has been studied for other medical applications as an inhibitor of amyloid $\beta$-peptide aggregation, whereas other hydroxyflavones such as quercetin failed to be effective (Lemkul \& Bevan 2012; Noor et al. 2012). Pyrrolidine had a significant effect in controlling biofilms with a $1 \mathrm{~h}$ exposure, while quercetin was highlighted for preventing biofilm formation. Also, several significant synergic combinations of antibiotics with the phytochemicals were obtained, notably the combinations between ciprofloxacin and quinine to control SA1199B biofilms ( $24 \mathrm{~h}$ exposure with a 2.1 $\log _{10}$ CFU cm$~^{-2}$ reduction) and between ciprofloxacin with reserpine to prevent SA1199B biofilm formation (a $3.2 \log _{10} \mathrm{CFU} \mathrm{\textrm {cm } ^ { - 2 }}$ reduction). These effects were dependent on the incubation time as longer exposure times and at non-lethal antibiotic doses, bacteria showed increased antibiotic tolerance. All the phytochemicals were able to increase the susceptibility of SA1199B to ciprofloxacin for nine days incubation, but after that only quinine and morin were successful in reducing antibiotic tolerance. Quercetin promoted the highest EPI activity in the SA1199B strain. In addition to the promising results promoted by selected phytochemicals in biofilm prevention and control, due to their extensive functional group chemistry and chirality those products are potentially interesting scaffolds for the discovery and development of antibacterial therapeutic approaches.

\section{Acknowledgements}

The authors are grateful to Professor Simon Gibbons (Department of Pharmaceutical and Biological Chemistry, The School of Pharmacy, UCL School of Pharmacy, London) for providing the bacterial strains.

\section{Disclosure statement}

No potential conflict of interest was reported by the authors.

\section{Funding}

This work was financially supported by: Laboratory for Process Engineering, Environment, Biotechnology and Energy (LEPABE) funded by FEDER funds through COMPETE2020-Programa Operacional Competitividade e Internacionalização (POCI) [project POCI-01-0145FEDER-006939]; and by national funds through Fundação para a Ciência e a Tecnologia (FCT)/MEC [grant numbers SFRH/BD/84393/2012 and SFRH/BPD/81982/2011].

\section{ORCID}

Manuel Simões (iD) http://orcid.org/0000-0002-3355-4398

\section{References}

Abreu AC, McBain AJ, Simões M. 2012. Plants as sources of new antimicrobials and resistance-modifying agents. Nat Prod Rep. 29:1007-1021. doi:http://dx.doi.org/10.1039/ c2np20035j

Abreu AC, Borges A, Malheiro J, Simões S. 2013. Resurgence of the interest in plants as sources of medicines and resistancemodifying agents. In: Mendez-Vilas A, editor. Microbial pathogens and strategies for combating them: science, technology and education. Badajoz: Formatex Research Center; p. 1287-1297.

Abreu AC, Serra SC, Borges A, Saavedra MJ, Salgado AJ, Simões M. 2014. Evaluation of the best method to assess antibiotic potentiation by phytochemicals against Staphylococcus aureus. Diagn Microbiol Infect Dis. 79:125-134. doi:http:// dx.doi.org/10.1016/j.diagmicrobio.2014.03.002

Abreu AC, Serra SC, Borges A, Saavedra MJ, Mcbain AJ, Salgado AJ, Simões M. 2015. Combinatorial activity of flavonoids with antibiotics against drug-resistant Staphylococcus aureus. Microb Drug Resist. 21:600-609. doi:http://dx.doi. org/10.1089/mdr.2014.0252

Bernier SP, Surette MG. 2013. Concentration-dependent activity of antibiotics in natural environments. Front Microbiol. 4:14. Article ID 20. doi:http://dx.doi.org/10.3389/ fmicb.2013.00020

Bridier A, Briandet R, Thomas V, Dubois-Brissonnet F. 2011. Resistance of bacterial biofilms to disinfectants: a review. Biofouling. 27:1017-1032. doi:http://dx.doi.org/10.1080/08 927014.2011.626899

Brooun A, Liu S, Lewis K. 2000. A dose-response study of antibiotic resistance in Pseudomonas aeruginosa biofilms. Antimicrob Agents Chemother. 44:640-646. doi:http:// dx.doi.org/10.1128/AAC.44.3.640-646.2000

Brown ED, Wright GD. 2016. Antibacterial drug discovery in the resistance era. Nature. 529:336-343. doi:http://dx.doi. org/10.1038/nature17042

Burmolle M, Webb JS, Rao D, Hansen LH, Sorensen SJ, Kjelleberg S. 2006. Enhanced biofilm formation and increased resistance to antimicrobial agents and bacterial invasion are caused by synergistic interactions in multispecies biofilms. Appl Environ Microbiol. 72:3916-3923. doi:http://dx.doi. org/10.1128/AEM.03022-05

Busetti A, Crawford DE, Earle MJ, Gilea MA, Gilmore BF, Gorman SP, Laverty G, Lowry AF, McLaughlin M, Seddon KR. 2010. Antimicrobial and antibiofilm activities of 1-alkylquinolinium bromide ionic liquids. Green Chem. 12:420-425. doi:http://dx.doi.org/10.1039/b919872e

Caiazza NC, O’Toole GA. 2003. Alpha-toxin is required for biofilm formation by Staphylococcus aureus. J Bacteriol. 185:3214-3217. doi:http://dx.doi.org/10.1128/JB.185.10. 3214-3217.2003

CLSI. 2003. Clinical and laboratory standards institute: performance standards for antimicrobial susceptibility 
testing - sixth edition: approved standard M7-A6. Wayne, PA: CLSI.

Costa SS, Viveiros M, Amaral L, Couto I. 2013. Multidrug efflux pumps in Staphylococcus aureus: an update. Open Microbiol J. 7:59-71. doi:http://dx.doi. org/10.2174/1874285801307010059

Couto I, Costa SS, Viveiros M, Martins M, Amaral L. 2008. Efflux-mediated response of Staphylococcus aureus exposed to ethidium bromide. J Antimicrob Chemother. 62:504-513. doi:http://dx.doi.org/10.1093/jac/dkn217

Cragg GM, Newman DJ. 2013. Natural products: a continuing source of novel drug leads. Biochim Biophys Acta (BBA) - General Subjects. 1830:3670-3695. doi:http://dx.doi. org/10.1016/j.bbagen.2013.02.008

Cushnie TPT, Lamb AJ. 2005. Antimicrobial activity of flavonoids. Int J Antimicrob Agents. 26:343-356. doi:http:// dx.doi.org/10.1016/j.ijantimicag.2005.09.002

Fux CA, Costerton JW, Stewart PS, Stoodley P. 2005. Survival strategies of infectious biofilms. Trends Microbiol. 13:3440. doi:http://dx.doi.org/10.1016/j.tim.2004.11.010

Gibbons S, Udo EE. 2000. The effect of reserpine, a modulator of multidrug efflux pumps, on the in vitro activity of tetracycline against clinical isolates of methicillin resistant Staphylococcus aureus (MRSA) possessing the Tet(K) determinant. Phytotherapy Res. 14:139-140. doi:http:// dx.doi.org/10.1002/(ISSN)1099-1573

Gibbons S, Oluwatuyi M, Kaatz GW. 2003. A novel inhibitor of multidrug efflux pumps in Staphylococcus aureus. J Antimicrob Chemother. 51:13-17. doi:http://dx.doi. org/10.1093/jac/dkg044

Gogoi-Tiwari J, Williams V, Waryah CB, Eto KY, Tau M, Costantino P, Tiwari HK, Mukkur T. 2015. Comparative studies of the immunogenicity and protective potential of biofilm vs planktonic Staphylococcus aureus vaccine against bovine mastitis using non-invasive mouse mastitis as a model system. Biofouling. 31:543-554. doi:http://dx.doi.or g/10.1080/08927014.2015.1074681

Holler JG, Christensen SB, Slotved H-C, Rasmussen HB, Guzman A, Olsen C-E, Petersen B, Molgaard P. 2012. Novel inhibitory activity of the Staphylococcus aureus NorA efflux pump by a kaempferol rhamnoside isolated from Persea lingue Nees. J Antimicrob Chemother. 67:1138-1144. doi:http://dx.doi.org/10.1093/jac/dks005

IDSA. 2011. Infectious Diseases Society of America (IDSA) combating antimicrobial resistance: policy recommendations to save lives. Clin Infect Dis. 52:S397-S428. doi:http://dx.doi. org/10.1093/cid/cir153

Jin J, Zhang J, Guo N, Feng H, Li L, Liang J, Sun K, Wu X, Wang X, Liu M, et al. 2011. The plant alkaloid piperine as a potential inhibitor of ethidium bromide efflux in Mycobacterium smegmatis. J Med Microbiol. 60:223-229. doi:http://dx.doi.org/10.1099/jmm.0.025734-0

Kaplan JB, Izano EA, Gopal P, Karwacki MT, Kim S, Bose JL, Bayles KW, Horswill AR. 2012. Low levels of $\beta$-lactam antibiotics induce extracellular DNA release and biofilm formation in Staphylococcus aureus. mBio 3:e00198-00112. doi:http://dx.doi.org/10.1128/mBio.00198-12

Kumar S, Pandey AK. 2013. Chemistry and biological activities of flavonoids: an overview. Sci World J. 2013:16. Article ID 162750. doi:http://dx.doi.org/10.1155/2013/162750

Lee J-H, Park J-H, Cho HS, Joo SW, Cho MH, Lee J. 2013. Anti-biofilm activities of quercetin and tannic acid against
Staphylococcus aureus. Biofouling. 29:491-499. doi:http:// dx.doi.org/10.1080/08927014.2013.788692

Lemkul JA, Bevan DR. 2012. Morin inhibits the early stages of amyloid $\beta$-peptide aggregation by altering tertiary and quaternary interactions to produce "off-pathway" structures. Biochemistry. 51:5990-6009. doi:http://dx.doi.org/10.1021/ bi300113x

Lewis K. 2013. Platforms for antibiotic discovery. Nat Rev Drug Discovery. 12:371-387. doi:http://dx.doi.org/10.1038/ nrd3975

Markham PN, Westhaus E, Klyachko K, Johnson ME, Neyfakh AA. 1999. Multiple novel inhibitors of the NorA multidrug transporter of Staphylococcus aureus. Antimicrob Agents Chemother. 43:2404-2408.

Monzon M, Oteiza C, Leiva J, Amorena B. 2001. Synergy of different antibiotic combinations in biofilms of Staphylococcus epidermidis. J Antimicrob Chemother. 48:793-801. doi:http://dx.doi.org/10.1093/jac/48.6.793

Mullin S, Mani N, Grossman TH. 2004. Inhibition of antibiotic efflux in bacteria by the novel multidrug resistance inhibitors Biricodar (VX-710) and Timcodar (VX-853). Antimicrob Agents Chemother. 48:4171-4176. doi:http:// dx.doi.org/10.1128/AAC.48.11.4171-4176.2004

Noor H, Cao P, Raleigh DP. 2012. Morin hydrate inhibits amyloid formation by islet amyloid polypeptide and disaggregates amyloid fibers. Protein Sci. 21:373-382. doi:http://dx.doi.org/10.1002/pro.2023

Olson M, Ceri H, Morck D, Buret A, Read R. 2002. Biofilm bacteria: formation and comparative susceptibility to antibiotics. Can J Vet Res. 66:86-92.

Oluwatuyi M, Kaatz GW, Gibbons S. 2004. Antibacterial and resistance modifying activity of Rosmarinus officinalis. Phytochemistry. 65:3249-3254. doi:http://dx.doi.org/10.1016/j. phytochem.2004.10.009

Pratt LA, Kolter R. 1998. Genetic analysis of Escherichia coli biofilm formation: roles of flagella, motility, chemotaxis and type I pili. Mol Microbiol. 30:285-293. doi:http://dx.doi. org/10.1046/j.1365-2958.1998.01061.x

Rodrigues L, Villellas C, Bailo R, Viveiros M, Ainsa JA. 2013. Role of the Mmr Efflux pump in drug resistance in Mycobacterium tuberculosis. Antimicrob Agents Chemother. 57:751-757. doi:http://dx.doi.org/10.1128/AAC.01482-12

Römling U, Balsalobre C. 2012. Biofilm infections, their resilience to therapy and innovative treatment strategies. J Int Med. 272:541-561. doi:http://dx.doi.org/10.1111/ joim.2012.272.issue-6

Schmitz FJ, Fluit AC, Luckefahr M, Engler B, Hofmann B, Verhoef J, Heinz HP, Hadding U, Jones ME. 1998. The effect of reserpine, an inhibitor of multidrug efflux pumps, on the in vitro activities of ciprofloxacin, sparfloxacin and moxifloxacin against clinical isolates of Staphylococcus aureus. J Antimicrob Chemother. 42:807-810. doi:http:// dx.doi.org/10.1093/jac/42.6.807

Shafahi M, Vafai K. 2010. Synthesis of biofilm resistance characteristics against antibiotics. Int $\mathrm{J}$ Heat Mass Transfer. 53:2943-2950. doi:http://dx.doi.org/10.1016/j. ijheatmasstransfer.2010.04.004

Simoes M, Rocha Silvia, Coimbra MA, Vieira M. 2008. Enhancement of Escherichia coli and Staphylococcus aureus antibiotic susceptibility using sesquiterpenoids. Med Chem. 4:616-623. doi:http://dx.doi.org/10.2174/15734060 8786242016 
Simões M, Bennett RN, Rosa EAS. 2009. Understanding antimicrobial activities of phytochemicals against multidrug resistant bacteria and biofilms. Nat Prod Rep. 26:746-757. doi:http://dx.doi.org/10.1039/b821648g

Smith AW. 2005. Biofilms and antibiotic therapy: is there a role for combating bacterial resistance by the use of novel drug delivery systems? Adv Drug Delivery Rev. 57:1539-1550. doi:http://dx.doi.org/10.1016/j.addr.2005.04.007

Smith E, Williamson M, Wareham N, Kaatz G, Gibbons S. 2007. Antibacterials and modulators of bacterial resistance from the immature cones of Chamaecyparis lawsoniana. Phytochemistry. 68:210-217. doi:http://dx.doi. org/10.1016/j.phytochem.2006.10.001

Tsuchiya H, Sato M, Miyazaki T, Fujiwara S, Tanigaki S, Ohyama M, Tanaka T, Iinuma M. 1996. Comparative study on the antibacterial activity of phytochemical flavanones against methicillin-resistant Staphylococcus aureus. J Ethnopharmacol. 50:27-34. doi:http://dx.doi. org/10.1016/0378-8741(96)85514-0

Verstraeten N, Braeken K, Debkumari B, Fauvart $M$, Fransaer J, Vermant J, Michiels J. 2008. Living on a surface: swarming and biofilm formation. Trends Microbiol. 16:496-506. doi:http://dx.doi.org/10.1016/j. tim.2008.07.004

Walberg M, Gaustad P, Steen HB. 1999. Uptake kinetics of nucleic acid targeting dyes in S. aureus, E. faecalis and $B$. cereus: a flow cytometric study. J Microbiol Methods. 35:167-176. doi:http://dx.doi.org/10.1016/S0167-7012(98) 00118-3

Wright GD. 2010. Antibiotic resistance in the environment: a link to the clinic? Curr Opin Microbiol. 13:589-594. doi:http://dx.doi.org/10.1016/j.mib.2010.08.005 